\title{
Disturbances in VHF/UHF telemetry links as a possible effect of the 2003 Hokkaido Tokachi-oki earthquake
}

\author{
H. Nagamoto ${ }^{1,2}$, T. Fukushima ${ }^{3}$, Y. Ida ${ }^{1,4}$, Y. Matsudo ${ }^{1,4}$, and M. Hayakawa ${ }^{1,4}$ \\ ${ }^{1}$ Research Station on Seismo Electromagnetics, The University of Electro-Communications, 1-5-1 Chofugaoka, \\ Chofu Tokyo 182-8585, Japan \\ ${ }^{2}$ Department of Information and Communication Engineering, The University of Electro-Communications, \\ Chofu Tokyo, Japan \\ ${ }^{3}$ Matsudo Municipal Matsudo High School, 2-7-5 Kamishiki, Matsudo, Chiba, Japan \\ ${ }^{4}$ Department of Electronic Engineering, The University of Electro-Communications, Chofu Tokyo, Japan
}

Received: 13 June 2008 - Revised: 9 July 2008 - Accepted: 9 July 2008 - Published: 5 August 2008

\begin{abstract}
The data on radio telemetry links (for water information) at VHF/UHF in Hokkaido are used to investigate the rate of disturbances on radio links (or connection failure) and its association with a huge earthquake, Tokachi-oki earthquake on 26 September 2003. Especially, the telemetry links at the Tokachi region closest to the earthquake epicenter, showed a significant increase in disturbances on radio links two weeks to a few days before the earthquake on the basis of analysis during a long interval from 1 June 2002 to 3 November 2007 (over 5 years). We suggest that these severe disturbances in VHF/UHF telemetry links are attributed to the generation of seismogenic VHF/UHF radio noises (emissions). Based on this idea, we have estimated that the intensity of these seismogenic emissions is on the order of 10 $19 \mathrm{~dB} \mu \mathrm{V} / \mathrm{m}$. Finally, the present result was compared with other physical parameters already obtained for this earthquake.
\end{abstract}

\section{Introduction}

There have been recently accumulated a lot of electromagnetic precursory phenomena of earthquakes (EQs) (e.g., Hayakawa, 1999; Hayakawa and Molchanov, 2002; Hayakawa and Molchanov, 2007; Molchanov and Hayakawa, 2008). Seismo-electromagnetic effects take place in the following two forms: the first one is radio emissions directly from the lithosphere in a wide-frequency range from DC/ULF, ELF/VLF up to VHF or so, and the second cate-

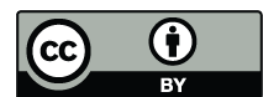

Correspondence to: M. Hayakawa (hayakawa@whistler.ee.uec.ac.jp) gory is that any seismic effect induces the perturbations either in the atmosphere or in the ionosphere, these being monitored in a form of propagation anomalies of the pre-existing transmitter signals (VHF and VLF) (e.g., see Hayakawa, 2007; Molchanov and Hayakawa, 2008).

This paper deals with the disturbances in the telemetry link at the frequency of VHF/UHF, which indicates that this is just the second category of radio probing mentioned above. However, the cause of these connection blackouts (or connection failures) in the VHF/UHF telemetry network is found to be possibly related to the radio emissions (noises) from the lithosphere which just belongs to the 1st category. Hence, this paper deals finally with both of the above two categories (or a combination of phenomena of the above two categories).

\section{EQ treated in this paper}

A huge EQ happened at $4 \mathrm{~h} 50 \mathrm{~min}$ L.T. on 26 September 2003 , and its epicenter was located at the geographical coordinates $\left(41^{\circ} 46^{\prime} 42^{\prime \prime} \mathrm{N}, 144^{\circ} 04^{\prime} 42^{\prime \prime} \mathrm{E}\right)$. This EQ is named 2003 Tokachi-oki EQ, whose magnitude is $\mathrm{M}=8.0$ and whose depth is $45 \mathrm{~km}$ (Shvets et al., 2004; Hayakawa et al., 2005). The epicenter is indicated as a cross in the Pacific Ocean in Fig. 1.

\section{Water flow measurements and the telemetry network of data transmission in the VHF/UHF band}

In order to monitor the natural hazard, especially the meteorological hazard, there are installed so many stations to monitor the rain fall and the associated water flow information

Published by Copernicus Publications on behalf of the European Geosciences Union. 


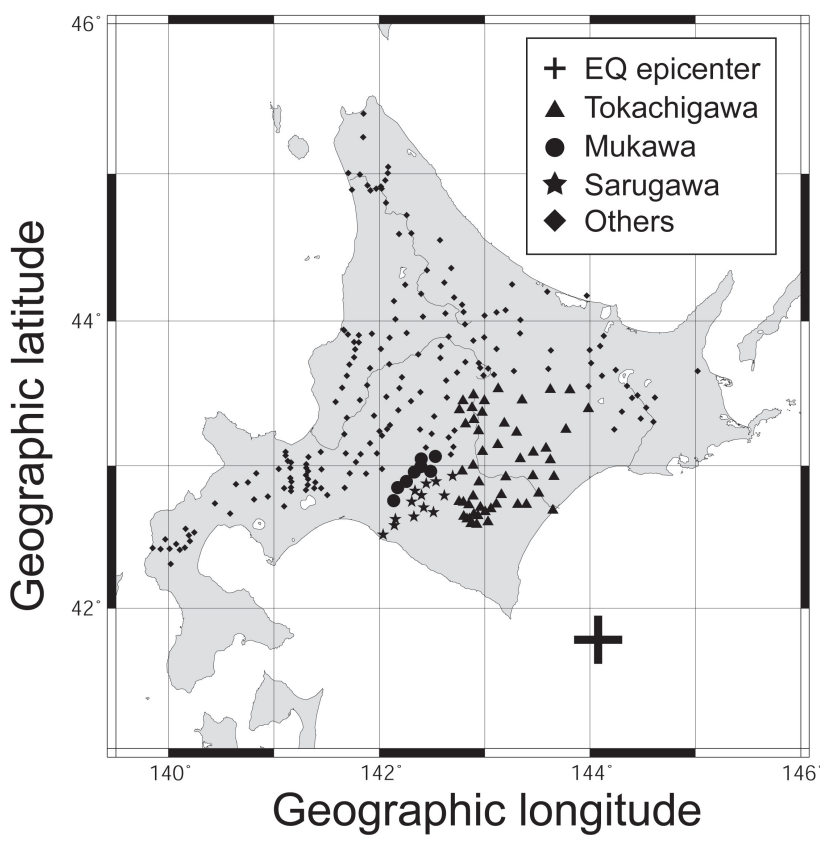

Fig. 1. Map showing the EQ epicenter (cross) and monitoring stations including three groups (Tokachigawa, Mukawa and Sarugawa).

of rivers all over Japan. Our initial motivation of the present study dates back to a discovery of disturbances in the VHF/UHF telemetry link at many stations in the Hokkaido area at the time of a huge EQ, 2003 Tokachi-oki EQ. That is, the data on water flow measurement at many stations were not transmitted to the corresponding master station just around the EQ.

So the purpose of this paper is summarized as follows.

1. Are there any disturbances on the VHF/UHF telemetry links (that is, connection blackout or failure)? If so, are they related to the $\mathrm{EQ}$ ?

2. Is this disturbance in the VHF/UHF telemetry link during the EQ, associated with the VHF radio noise (as compared with the normal-time signal intensity)?

Here we have to explain the system of measuring the water parameters (rain fall, water flow of rivers, etc.). Within the area of Hokkaido, there have been established 241 monitoring stations which have been run by Ministry of Land, Infrastructure, Transport and Tourism for the sake of mitigation of natural hazards. Those 241 stations are grouped into several clusters, each being closely affiliated with the river. The data observed at stations in a group are collected at a master station of the group every hour, and the data are distributed to the public by internet. This data transmission from the slave stations to the master station in each group, is performed by means of radio link only in this Hokkaido area. The characteristics of VHF/UHF telemetry links are summarized in Table1.

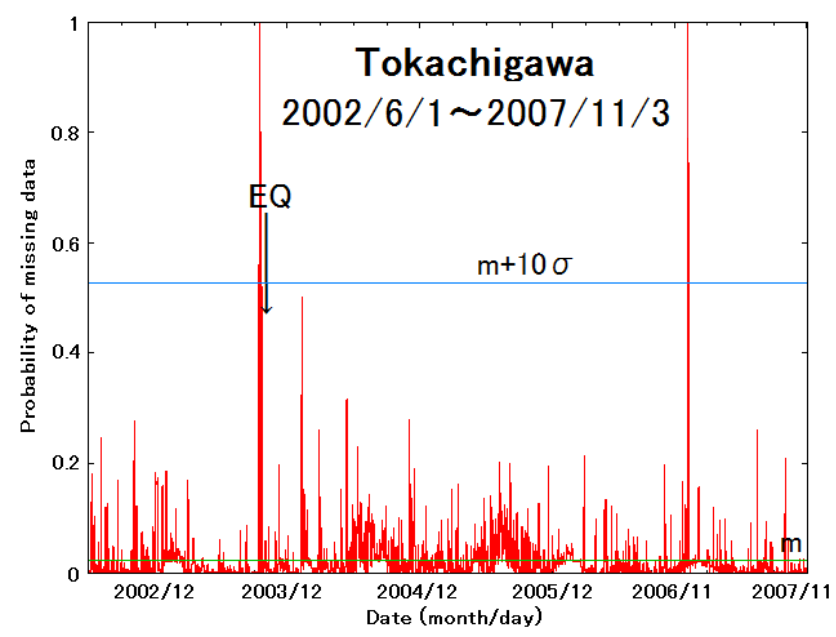

Fig. 2. Temporal evolution during more than 5 years (1 June 2002 to 3 November 2007) of the probability of missing telemetry links for a particular group of Tokachigawa. EQ indicates the day of 2003 Tokachi-oki EQ. The mean is indicated by $\mathrm{m}$ and our threshold of $\mathrm{m}+10 \sigma(\sigma:$ standard deviation $)$ is also indicated.

We now define the missing transmission between the master station and its affiliated monitoring (slave) stations in a group. Every hour the master station sends a request to the 1 st monitoring station, and the water data at this station are sent back to the master station. This procedure is repeated successively for all monitoring stations in the group one by one. When there might be any monitoring station which has not sent back the data, the master station does send another request to this monitoring station. Even in this situation when the monitoring station does not send back the data to the master station, we define this as the missing transmission (or connection failure).

\section{Analysis method}

By grouping the monitoring stations based on the same transmission frequency and the same master station, we use the following three groups among the 16 groups in Hokkaido: (1) Tokachigawa (Tokachi river) group, (2) Mukawa (Mu river) group and (3) Sarugawa (Saru river) group. They are indicated in Fig. 1, with different notations for different groups. As shown in Fig. 1, the number of monitoring stations is 50 for the group of Tokachigawa, 8 for Mukawa group and 13 for Sarugawa group. Then, we count the number of missing transmission for each of the three groups. During this process, we have excluded the events of missing transmission when there are missing transmission definitely due to the maintenance of the telemetry links (missing transmission at all monitoring stations in Hokkaido). Then, we estimate the percentage occurrence of missing transmission every hour for each group and we study the average running over $\pm 12 \mathrm{~h}$. 
Table 1. Characteristics of VHF/UHF telemetry transmission.

\begin{tabular}{ll}
\hline No. of monitoring stations & 241 \\
\hline Frequency & $70 \mathrm{MHz}, 400 \mathrm{MHz}$ (the ratio of use of these two frequencies being $\sim 9: 1)$ \\
Transmission power & $1 \mathrm{~W}, 3 \mathrm{~W}, 5 \mathrm{~W}, 10 \mathrm{~W}$ (the use of a connecting station for the power $\lesssim 3 \mathrm{~W}$ ) \\
Possible transmission range & $70 \mathrm{MHz}: 20 \sim 30 \mathrm{~km} 400 \mathrm{MHz}: 20 \mathrm{~km}$ (mainly $70 \mathrm{MHz}$ in the mountain area) \\
\hline Antennas (Tx and Rx) & Yagi antenna (normally 3-elements Yagi, vertical polarization) \\
\hline
\end{tabular}

\section{Analysis results}

The data analysis is performed during the period from 1 June 2002 to 3 November 2007 (over 5 years). First, we illustrate the temporal evolution of the probability of missing data transmission for the group (Tokachigawa) closest to the EQ epicenter in Fig. 2. Here we estimate the mean value (m) of the probability of missing data and also the standard deviation $(\sigma)$ is also estimated. We impose a criterion (or threshold) of $\mathrm{m}+10 \sigma$, and Fig. 2 indicates that there are two obvious anomalies, one in September, 2003 and another, in December, 2006.

The detailed or enlanged temporal evolutions of missing link connection for the two anomalous periods of September 2003 and December 2006, are illustrated in Figs. 3 and 4, respectively. For both cases, all of three groups are presented in both figures; from the top, Tokachigawa, Mukawa and Sarugawa groups. Figure 3 indicates a few possible periods of high missing link connections on 12 September (20-22 hL.T.), 14-15 September (14 September, $9 \mathrm{~h} \sim 15$ September $17 \mathrm{~h}$ ), 20 September (20 September $9 \mathrm{~h} \sim 21$ September $1 \mathrm{~h}$ ), and 23 September $(9 \sim 18 \mathrm{~h})$ and 24 September $(1 \sim 2 h)$, all just before the EQ. The duration of anomalies is found to range from a few hours to $33 \mathrm{~h}$. As compared to the high rate of missing link connection for the Tokachigawa group, those of missing link connection for the other two groups of Mukawa and Sarugawa, are found to be considerably less enhanced. However, we find still sufficiently high missing data transmission on 15 (September $1 \sim 17 \mathrm{~h})$ and 23 September $(9 \sim 18 \mathrm{~h})$. These anomalies are likely to be a precursory effect of this EQ. The different behavior in the missing rate seems to be closely related with the distance of each group to the $\mathrm{EQ}$ epicenter.

While, Fig. 4 indicates that the anomalous telemetry link disturbance for the December 2006 event, is taking place only at Tokachigawa, but nothing in other two groups of Mukawa and Sarugawa. Therefore, it is high likely that this is not a natural phenomenon, even though we do not know the reason for this.

\section{Discussion on the cause of disturbances in VHF/UHF telemetry links}

The observation system of water flow is required to be stable except at some special situations such as the maintenance etc. The VHF/UHF telemetry communication is generally designed so as to maintain the minimum $\mathrm{S} / \mathrm{N}$ ratio of $30 \mathrm{~dB}$. However, because of the unstable nature of natural noises (due to diurnal and seasonal changes), we normally assume an additional margin of $2 \sim 3$ times. This is the design criterion of these water flow system telemetry requirements. By taking into account this criterion by the Ministry of Lands, Infrastructure, Transport and Tourism, the company responsible for the maintenance and observation seems to provide a further margin of about 1.5 2.0 times to ensure the stable telemetry links. By taking full consideration of these facts together, we can conclude that we expect missing data transmission only when there must be VHF/UHF noises whose intensity is, at least, $2 \sim 6$ times the background noise level. We assume that the noises (or emissions) in VHF/UHF in possible association with an EQ are attributed to no data transmission (connection failure). This can be easily imagined from Figs. 1, 2 and 3 that the usual percentage of missing data transmission is sufficiently small, at maximum, $1 \sim 2 \%$.

The usual noise level in VHF/UHF band is $\sim 7 \mathrm{~dB} \mu \mathrm{V} / \mathrm{m}$ in an area with high city noises, $\sim 3 \mathrm{~dB} \mu \mathrm{V} / \mathrm{m}$ in residential areas and $\sim 2 \mathrm{~dB} \mu \mathrm{V} / \mathrm{m}$ in the mountaneous areas. On the supposition that the Ministry would adopt the noise level as twice the minimum detectable electric field and then the maintenance company would adopt a margin of twice the criterion by the Ministry, the noise probably related to the EQ should be more intense by $+12 \mathrm{~dB}$ than the background noise level. As the conclusion the seismogenic noise is expected to be $19 \mathrm{~dB} \mu \mathrm{V} / \mathrm{m}$ in the city areas, $15 \mathrm{~dB} \mu \mathrm{V} / \mathrm{m}$ in the residential areas and $10 \mathrm{~dB} \mu \mathrm{V} / \mathrm{m}$ in the mountaneous areas. The noises of this order are expected to have occurred prior to the EQ.

\section{$7 \quad$ Summary and discussion}

The data on water observation during five years from 2002 to 2007 are utilized to estimate the transmission blackout of observational data, which are compared with the occurrence of an EQ (Tokachi-oki EQ). The telemetry group of 

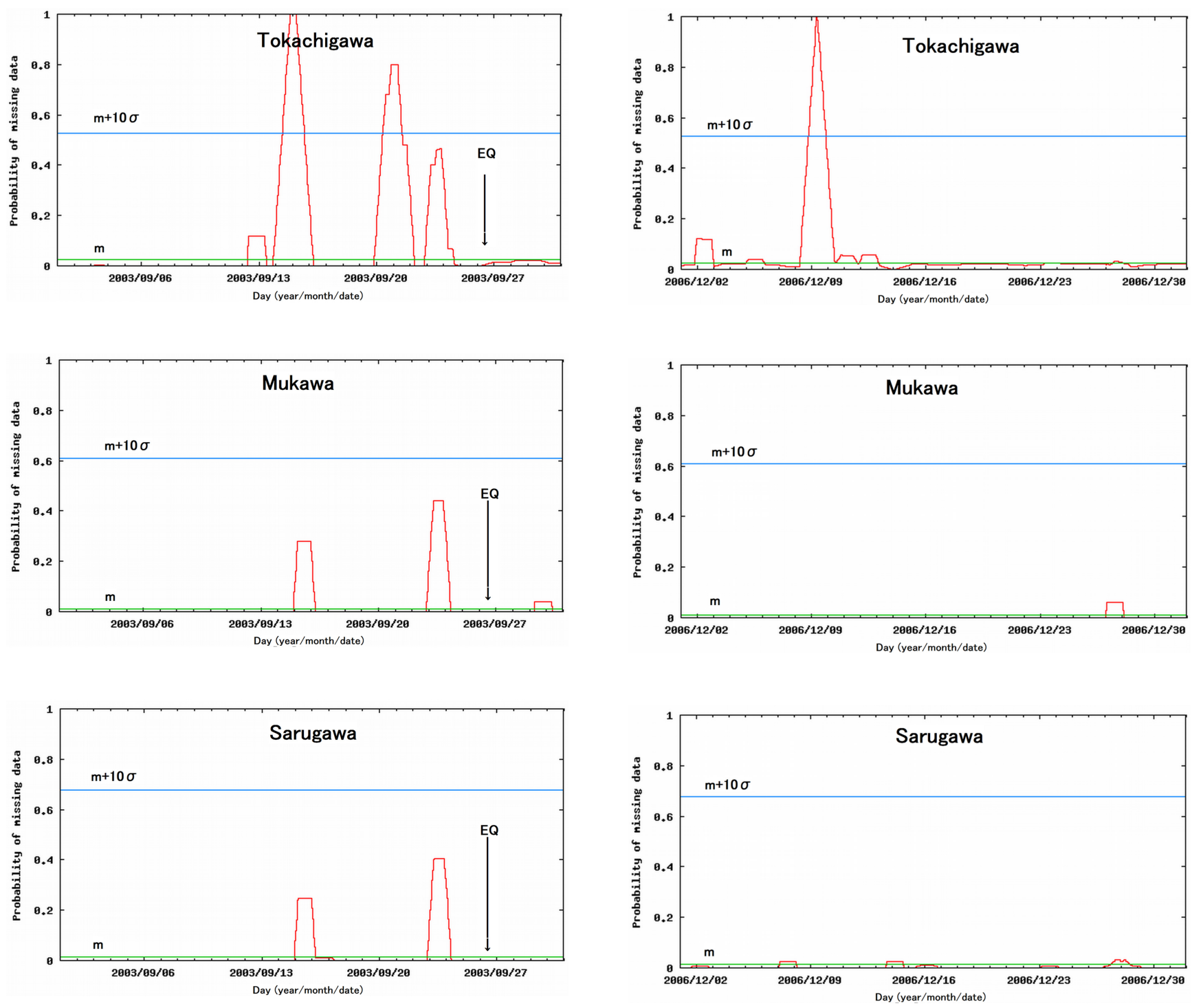

Fig. 3. Temporal evolutions of probability of missing data transmission for three different groups (from top, Tokachigawa, Mukawa and Sarugawa) for the anomalous event in September 2003.

Tokachigawa closest to the EQ epicenter, has shown a significant increase in transmission failure, suggesting a lot of noises on the telemetry links as radio disturbances. Only before the EQ, the percentage of missing telemetry links has increased a lot; 12, 14, September September 20, 21 and 23, 24 September; two weeks to a few days before the EQ. By using the characteristics of telemetry characteristics, we have speculated the electric field intensity of seismogenic noises of the order of $10-19 \mathrm{~dB} \mu \mathrm{V} / \mathrm{m}$.

This kind of radio disturbances on VHF/UHF telemetry links has already been reported by Kolvankar (2008), who has found the radio disturbances on UHF telemetry links (for the data transmission of seismic signals) in possible association with an EQ sequence in India. Principally, our paper

Fig. 4. The same as Fig. 3, but for another anomalous event in December 2006.

deals with the same topic, but for a particularly huge EQ, Tokachi-oki EQ and by using telemetry links for the data transmission of water information. It is found that seismogenic radio noises in UHF band are generated near Tokachi area, being close to the epicenter. They tend to be generated on 12, 14 September, 20, 21 September and 23, 24 September before the EQ.

We compare our result with former results for this EQ. Enomoto et al. (2006) have reported on the presence of high frequency (HF) (the exact frequency range is not known) noises during the whole period of 25 August to 25 September in Hokkaido. The frequency is not exactly the same as ours, but the general tendency of having seismogenic high frequency radio noises nearly in the similar period, anyway before the $\mathrm{EQ}$, seems to be consistent with the present 
conclusion. For this EQ, our previous analysis of subionospheric VLF/LF data (for example, from a Japanese JJY station (in Fukushima) to Moshiri, Hokkaido and to Kamchatka, Russia) has indicated that the ionosphere was disturbed about one week before the EQ (Shvets et al., 2004; Hayakawa et al., 2005). In good correspondence to this ionospheric perturbation, Cervone et al. (2006) has found the anomaly in surface latent heat flux before the EQ. The period of these anomalous phenomena seems to be coincident with that obtained in the present paper. So, Earth's surface in the Tokachi area of Hokkaido is likely to be disturbed before the EQ leading to the generation of radio emissions near the Earth's surface or of some geochemical effect in possible association with the ionospheric perturbation, though detailed mechanisms are not well understood but need to be studied in future.

Acknowledgements. The authors would like to thank NiCT for its support (R\&D promotion scheme funding international joint research).

Edited by: P. F. Biagi

Reviewed by: two anonymous referees

\section{References}

Cervone, G., Maekawa, S., Singh, R. P., Hayakawa, M., Kafatos, M., and Shvets, A.: Surface latent heat flux and nighttime LF anomalies prior to the $\mathrm{M} \omega=8.3$ Tokachi-Oki earthquake, Nat. Haz. Earth Sys. Sci., 6, 109-114, 2006.

Enomoto, Y., Hashimoto, H., Shirai, N., Murakami, Y., Mogi, T., Takada, M., and Kasahara, M.: Anomalous geoelectric signals possibly related to the $2000 \mathrm{Mt}$. Usu eruption and 2003 Tokachioki earthquakes, Phys. Chem. Earth, 31, 319-324, 2006.

Hayakawa, M.: Atmospheric and Ionospheric Electromagnetic Phenomena Associated with Earthquakes, Terra Sci. Pub. Co., Tokyo, p. 996, 1999.

Hayakawa, M. and Molchanov, O. A.: Seismo Electromagnetics: Lithosphere - Atmosphere - Ionosphere Coupling, TERRAPUB, Tokyo, p. 477, 2002.

Hayakawa, M., Shvets, A. V., and Maekawa, S.: Subionospheric LF monitoring of ionospheric perturbations prior to the Tokachi-oki earthquake and a possible mechanism to lithosphere-ionosphere coupling, Adv. Polar. Upper Atmos. Res., 19, 42-54, 2005.

Hayakawa, M.: VLF/LF radio sounding of ionospheric perturbations associated with earthquakes, Sensors, 7, 1141-1158, 2007.

Hayakawa, M. and Molchanov, O. A.: Seismo-electromagnetics as a new field of radiophysics: Electromagnetic phenomena associated with earthquakes, Radio Science Bull., no. 320, 8-17, 2007.

Kolvankar, V. G.: Diurnal and semi-diurnal pattern of EM emissions related to earthquakes and volcanoes, in: Electromagnetic Phenomena Related to Earthquakes and Volcanoes, edited by: Singh, B., Narosa Pub. House, 15-29, 2008.

Molchanov, O. A. and Hayakawa, M.: Seismo Electromagnetics and Related Phenomena: History and latest results, TERRAPUB, Tokyo, p. 189, 2008.

Shvets, A. V., Hayakawa, M., and Maekawa, S.: Results of subionospheric radio LF monitoring prior to the Tokachi $(\mathrm{m}=8$, Hokkaido, 25 September 2003) earthquake, Nat. Haz. Earth Sys. Sci., 4, 647-653, 2004. 